\title{
AN ANALYSIS OF ONE HUNDRED CASES OF FITS IN CHILDREN
}

BY

\author{
S. HAROLD COOKSON, M.D., B.Sc., M.R.C.P.
}

Medical Registrar, Middlesex Hospital.

From the Hospital for Sick Children, Great Ormond Street, London.

This analysis of one hundred cases of fits in children was undertaken at the Hospital for Sick Children, Great Ormond Street, with the object of discovering the clinical associations of the convulsions, classifying them retiologically, as far as possible, and determining the effect of treatment.

The children examined varied in age from six weeks to eleven and a half years. By far the most were aged one year or less at the time of onset. Less than half this number began in the second year of life, while in the third year the incidence again rose. After this the incidence of cases gradually diminished; only one case $(1 \%$ ) had fits for the first time in the twelfth year of life.

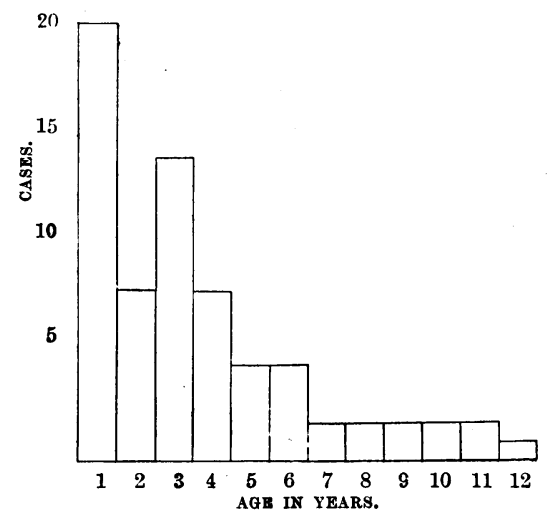

Fig. 1. The Age of Onset of Fits (100 cases).

Fifty-five cases were boys, and forty-five girls ; in $20 \%$ of cases there was a family history of epilepsy. In one case there was a family, and a personal history of eczema. There was a personal history of cyclic vomiting in one case ; in no case was there a family history of cyclic vomiting, asthma, gout, or urticaria. In eighteen instances, there was a history of difficult labour. In twenty-six cases there was a deficiency of mentality, more or less marked; in all the others it was normal. Where mental deficiency was present, it had been noticed as early as the fits ; in two cases, mental impairment was stated to be progressive. Of the cases with mental deficiency, eight were born with difficulty; one precipitately, the child's head striking the ground ; six had spastic 
diplegia; one was a mongol, one was regarded as post-encephalitic mental deficiency, and two were microcephalic.

The following were the associated clinical conditions noted :-

\begin{tabular}{|c|c|}
\hline Spasmophilia & \\
\hline Threadworms & 2 \\
\hline Teething .... & 5 \\
\hline Tuberculous meningitis. & 1 \\
\hline Rickets & 3 \\
\hline Diphtheria & 1 \\
\hline After Measles & 1 \\
\hline Broncho-pneumonia ... & 1 \\
\hline Constipation.............. & j \\
\hline Head injury............ & \\
\hline
\end{tabular}

The weights of the patients have been plotted on a graph, together with a curve representing average weight from birth to 12 years. It will be seen that the dots are arranged almost symmetrically about the curve, only a slight excess being found below the curve; this indicates that the average weight of the patients is not much below normal.

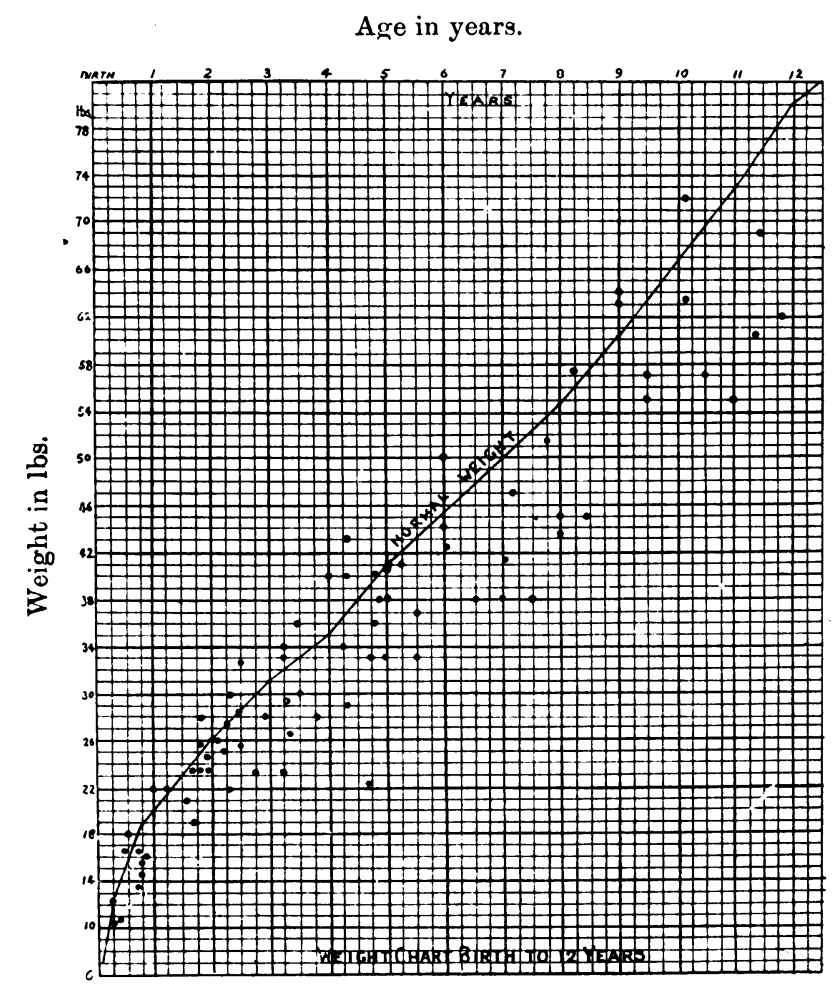

Fig. 2.

Weights of 100 children suffering from Fits, compared with the normal weight curve $(0-12$ years). 
Nature of the Fits.

Cases of petit mal, using the term to include cases in which loss of conscious. ness was incomplete, were about as numerous as those who suffered from grand mal alone. A relatively small number had both kinds of fit, and in three cases a history was given that whereas the child used to suffer from petit mal this had been replaced in the course of time by major fits. Several varieties of petit mal were met with, but no case was seen of the type termed pyknolepsy, defined by Adie $\left({ }^{1}\right)$ as " a disease with an explosive onset between the ages of 4 and 12 years, of short, very slight monotonous, minor epileptiform seizures, of uniform severity, which persist for weeks, months or years, uninfluenced by anti-epileptic remedies, without impeding normal mental and physical development, and ultimately cease spontaneously, never to recur." There was one child who fitted in with this definition so far as the individual attacks, which were sometimes repeated 40 times daily, were concerned; but the onset was at the age of two, and a year later, he started to have grand mal. There was one interesting case in which the attacks occurred with a frequency varying from a dozen to several score daily. Each consisted of a forward nodding of the head, with a vacant look in the eyes and a twitching of the mouth, lasting about 15 seconds. In the later attacks there was in addition a rhythmic twitching of the arms. The legs were held stiffly if the child was seated when the attack occurred, but no movement occurred in them. In another case the fit consisted in a momentary vacancy with twitching of the hands; in a third there was a glassy look in the eyes, copious salivation, and the left arm was abducted from the side and drawn backwards, and the left corner of the mouth was drawn down. The remainder of the group consisted of cases in which there was merely a transient loss of consciousness unaccompanied by any motor phenomena.

Considering the stage of mental development of the patients, a history of an aura was not often to be expected; it was only elicited in two casesone a girl of 11, who suffered from grand mal, had a visual aura; the other, also a girl of 11, had a headache before a series of petit mal attacks. In many instances, however, the mother said that she could tell from the child's behaviour when an attack was about to occur. In one case a characteristic change was noted several days before the fit actually occurred. Most of the patients with petit mal, recovered rapidly from their attacks ; a few complained of headache, one of loss of memory, and one boy of five had periods of automatism,

The patients with grand mal composed half the total. In four instances fits occurred only at night ; in the remainder, they occurred by day and night, or by day only. The cases with established epilepsy were investigated, first, with the object of deciding what exciting factors were concerned in the fits. In four constipation was considered all-important by the parent; in these it was invariably noted that constipation was severe at the time of the fit. Excitement was another factor; in some cases fits were more numerous or occurred only at the week-end; some unwonted excitement at this time was 
probably the explanation for this; larger and richer meals may also have played a part. A total and differential white blood count was made in eleven cases. These showed an average white cell count of 8,000 , while the various types of white cells were present in proportions which could be regarded as normal considering the ages of the patients. Eosinophil polymorphs averaged $1 \%$. The blood was grouped in nine cases; the results were as follows :-

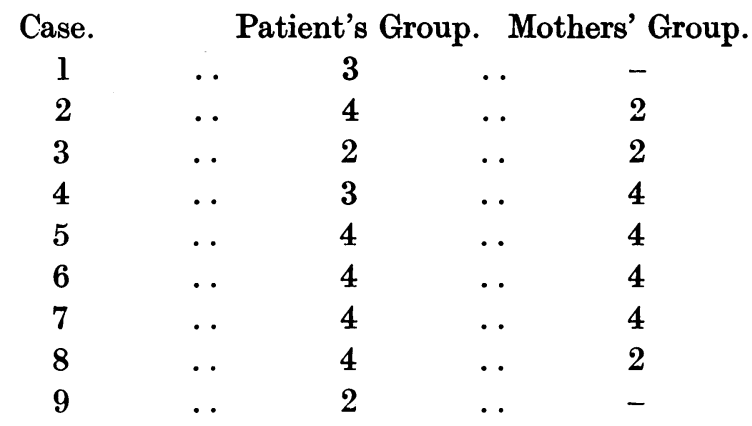

The distribution of the patients in the different groups corresponds roughly with that of normal individuals, and there is no striking relationship between the blood groups of mother and child.

Lumbar puncture was performed in six cases. No abnormality was discovered in the cerebro-spinal fluid. The protein, chloride, cell, and sugar content were all normal. In all cases the Wassermann reaction was negative. The blood W.R. was also negative throughout the series. The fundus oculi was examined in all cases, and found normal in every one.

\section{Treatment.}

The two main methods of treatment used were the usual ones of bromide and luminal. Twenty-five cases of major epilepsy were treated with sodium luminal combined with 10-minim doses of tincture of belladonna. Of these 21 were benefited, two were not improved, and in the remaining two the fits became worse. In many cases the effect of the drug was striking, and in 11 out of the 21 cases that derived benefit, the improvement could be described as very great. The selective action of the drug was demonstrated in one case of combined petit and grand mal. The patient, a girl aged 3, had no major attack for four months after being given luminal, but minor attacks continued with the same frequency as before treatment. The dose of luminal used was variable, and depended, not on the patient's age, but on the individual response. In some cases there was remarkable improvement on $\frac{1}{2}$ grain daily ; in others $\frac{3}{1}$ grain was given daily to get the best results ; this dose, $1 \frac{1}{2}$ grains twice daily, was the maximum. Two cases, treated first with bromide and chloral, with little or no benefit, did well when luminal was substituted. Six cases were treated with potassium bromide ; in three the number of fits was uninfluenced; in three they were diminished. 
Two cases of spasmophilia were improved with chloral and hydrarg. cum creta, and two other cases which were given cod liver oil and malt and ammonium chloride were rapidly cured. One patient was treated with bromides, and then with luminal, the only result being an increase in the number of fits. As a last resort sub-temporal decompression was done; convulsions started on the evening of the day of operation, and continued till the death of the patient. Post-mortem showed there was no gross lesion except a minute hæmorrhage in the cortex under the site of the decompression. An interesting feature in the history of this case was that the fits stopped temporarily after measles.

TABLE SHOWING EFFECT OF VARIOUS METHODS OF TREATMENT.

\begin{tabular}{|c|c|c|c|c|c|c|c|c|c|}
\hline \multirow[b]{2}{*}{$\begin{array}{l}\text { Method of } \\
\text { Treatment. }\end{array}$} & \multicolumn{5}{|c|}{ Grand MaL. } & \multicolumn{4}{|c|}{ Petti Mal. } \\
\hline & $\begin{array}{c}\text { Total } \\
\text { Treated. }\end{array}$ & $\begin{array}{l}\text { Great } \\
\text { Imp. }\end{array}$ & $\begin{array}{l}\text { Mod. } \\
\text { Imp. }\end{array}$ & $\begin{array}{l}\text { No } \\
\text { Imp. }\end{array}$ & Worse. & $\begin{array}{l}\text { Total } \\
\text { Treated. }\end{array}$ & $\begin{array}{l}\text { Great } \\
\text { Imp. }\end{array}$ & $\begin{array}{l}\text { Mod. } \\
\text { Imp. }\end{array}$ & $\begin{array}{l}\text { No Imp. } \\
\text { or worse. }\end{array}$ \\
\hline $\begin{array}{c}\text { Sod. luminal and Tr. } \\
\text { belladonnæ }\end{array}$ & 25 & 11 & 10 & 2 & 2 & 15 & 4 & 2 & 9 \\
\hline Bromide and Chloral & 2 & 0 & 0 & 2 & 0 & & & & \\
\hline Bromide & 6 & $\mathbf{0}$ & 3 & 3 & 0 & 3 & 1 & 1 & 1 \\
\hline
\end{tabular}

The results of treatment in the cases of petit mal were less successful. Fifteen cases were treated with sodium luminal; in only six did it have a favourable effect; four showed marked, two only slight improvement. In nine cases the drug was either without effect, or made the condition worse. The dosage employed, and mode of administration were the same as used for grand mal. Three patients were given potassium bromide; one was greatly improved, another moderately improved, and the third unchanged. One case which resisted all drug treatment was admitted to hospital and treated with the ketogenic diet. No decline in the number of attacks was noticed-they were occurring at the rate of $10-12$ daily during the period of treatment-nor did the number increase when the diet was left off. One other case which was resistant to all forms of drug treatment received a special form of treatment. The patient was a girl aged 9 months, who had frequent attacks of petit mal. There was a history of a difficult labour, and difficulty in getting the child to breathe after birth. A decompression in the left parietal region was done, with encouraging results. The number of attacks was considerably reduced.

\section{Discussion.}

The first noticeable point is the heary incidence of the disease in infants less than one year old. Fits occurring at this age are usually associated with trivial ailments such as constipation and teething; in many cases they are 
recovered from, and there is no recurrence. But on the other hand many of the cases in this series which had their first fits in early infancy continued to have fits for years afterwards. Of the twenty-three cases in which the onset was in the first year of life, fourteen continued to have fits during the several years they were under observation. The occurrence of convulsions in infancy and their recurrence in childhood after several years of freedom is well known; two examples of this phenomenon were met with. In one case fits occurred at the age of one, and then there was complete freedom for four years, when at the age of five they recurred. In the other there were attacks in infancy ; then, again, when the child had pneumonia at three; and then none for two years. From the age five till twelve fits were frequent; at the latter age the child passed from observation. A history of heredity was presented by $20 \%$ of cases-a figure which corrseponds closely with that usually given. It was $35 \%$ in Gower's cases, and $16 \%$ in Spratling's series of 2,523 cases. The sex incidence was found to be roughly equal.

There are many features of epilepsy which suggest an analogy with diseases nowadays thought to be due to an abnormal sensitiveness of the tissues-such as asthma, urticaria, eczema, cyclic vomiting and gout. This investigation revealed, however, practically no association of epilepsy with any of these diseases. A high eosinophil leucocyte count may be found in this type of disease; but in none of the cases under investigation in which blood counts were done, were these cells unusually numerous. Total white cell counts were uniformly within normal limits also. The features of the hæmoclastic crisis of Widal are stated by Bossard immediately to precede an attack. The good fortune to make a blood count immediately before an attack was only realised in one instance, and in this case no leucopenia was present (W. B. C., 7,000). Another feature of Widal's crisis is a fall in blood pressure. There was no opportunity of estimating the blood pressure just before a fit in these cases, but several observers have reported such a fall; it is difficult to know whether this should be regarded as cause or effect. Those investigations which are detailed here are, therefore, not such as will support the view that epilepsy is the result of tissue sensitisation.

Endogenous toxic products have been considered a cause, and this is generally conceded to be the mechanism of the fits of uræmia and eclampsia, of severe liver disorders, and of some pituitary and thyroid diseases. In these conditions the morbid changes are so gross that it is not difficult to believe that there may be a perversion of metabolism with the production of a toxic substance. But in the cases of idiopathic epilepsy so-called, such changes are conspicuous by their absence. Cuneo (quoted by Osnato) believes the primary defect in metabolism occurs in the intestine. He gives the following account of the process : citrates, alkaline tartrates, and other organic salts when painted on the motor cortex produce convulsions; in the normal subject such substances are produced in the gut, but are converted into bicarbonates, a process which begins in the gut and is completed in the liver. In epileptics this transformation fails to occur; the organic acids reach the 
brain and there have an action on the nucleo-histones of the cell-nuclei which results in the precipitation of nucleinic acid, and a base which has all the properties of proteose remains in solution. The latter is capable of producing typical convulsions in animals. Cuneo attempted to combat these dangers, by giving alkalis by the mouth, a low starch diet, and the subcutaneous injection of nucleinic acid in alkaline solution. He claimed good results. Some investigators believe vaso-constriction in the region of the motor cortex to be the cause of epilepsy; and fits have been produced experimentally in this way. Cuneo believes that here also the mechanism he describes is involved, the anæmia resulting from vaso-constriction leading to increased acidity of the tissues, and consequent liberation of a proteose-like substance from nucleohistone.

Directly opposed to the above view is one which has its origin in America. This supposes that epilepsy results not from an acidosis but from an alkalosis, since acidosis is associated with many of the conditions having a favourable effect on epilepsy ; for example, ether anæsthesia, and acute infections during and after which epilepsy may subside. A form of treatment based on this view has been evolved; it consists in a diet rich in fat and poor in carbohydrate (ketogenic diet). Such a diet tends to alter the reaction of the blood in the direction of acidity, and starvation has the same effect. The exponents of this method report good results-a temporary amelioration of the epileptic symptoms in some cases, a complete disappearance of the attacks in others, that is, up to the time of publication, the periods of observation being not longer than six months. In the one case of the present series treated by this method, no benefit whatever was observed. Some authors of the various explanations which have been suggested for the production of idiopathic epilepsy also apply their views to those cases of fits associated with gross changes within the cranium. Cuneo, for example, supposes that in cerebral tumours, tissue breaks down with the liberation of the convulsant proteose. Again, Sargent explains the fits following cranial trauma, as being the result of reflex vaso-constriction from tension or adhesions. Such vaso-constriction, according to Cuneo, would produce convulsions by the decomposition of nucleohistone as described above. Possibly the fits occurring in cases of spastic diplegia, and in cases giving a history of difficult labour, are to be explained along these lines.

A distinct line of thought finds its expression in the psychogenic conception of epilepsy. This was propounded by Pierce-Clark who defines epilepsy as a "psycho-biological reaction which is a refuge from an intolerable adjustment demand, and which constitutes a regression to a primitive pleasurable state." On this view the condition arises from a primary psychological defect. The mentality of the patient is characterised by egocentricity, hypersensitiveness, and emotional poverty. Such individuals find the strain of trying to cope with their environment too great, and escape from it by means of a fit. But a purely psychological explanation is obviously inadequate, since the mechanism of a physical process must be, essentially, a physical one. As a matter of fact, 
however, mental processes do play a considerable part in the disease under consideration; epilepsy sometimes arises in the adult after a prolonged period of mental strain, and such cases were not uncommon as a result of the war. Also depressing or exciting emotion may be the immediate precursor of the individual attack; as was noted in many of the children investigated. A suggestion of the link between these mental changes and the physical basis of an epileptic attack is provided by some work of Cannon's. Experimenting on cats, this observer showed that prolonged painful stimuli, and conditions of fear or anger, lead to an increase in adrenalin content of the blood. The increased concentration of this hormone in the blood may lead to constriction of the cerebral arterioles, and so produce a convulsion. This sequence of changes, vaso-constriction followed by a fit, is observed when adrenalin is painted on the cortex. The psychogenic conception will probably only be the explanation in a small number of cases, and would seem to have its most limited application in children, in whom the "adjustment demand" is not likely to be so intolerable as to produce convulsions.

Epilepsy has been a common disease since the time of Hippocrates, yet we know little more about it than this observer. The modern trend of opinion is towards some metabolic disturbance as being the cause; our ignorance as to what this distrubance is, is sufficiently indicated by the multiplicity and mutual antagonism of the various views taken of its nature.

A comparison of the results of treatment with various drugs shows that luminal gave easily the best results. In all cases it was combined with tincture of belladonna. The results are very different in the major type of fits, from those obtained in the minor cases. In the latter only a minority are improved, although the results are better than with any other drug. In the treatment of major fits in children, luminal was found, combined with belladonna, to be a distinct advance on bromides. Using two other methods of treatment, the ketogenic diet, and cerebral decompression, no benefit was obtained using the former in one case, while the latter resulted in definite relief in one case, but proved fatal in another.

The observations recorded here were made on patients attending Dr. Donald Paterson, to whom I am indebted for help.

\section{REFERENCES.}

1. Adie, W. J., Proc. Roy. Soc. Med., Lond., 1923-24, XVII, (Sect. Neurol.), 19.

2. Osnato, M., Arch. Neurol. and Psych., Chic., 1923, IX, 488.

3. Peterman, M. G., Med. Clin. N.Am., Phila., 1925, VIII, 1351.

4. Hoeffel, G. N., and Moriarty, M. E., Am. J. Dis. Child., Chic., 1924, XXVIII, 16.

5. Sargent, P., Brain, Lond., 1921, XLIV, 312. 